\title{
Supervision Practices between School Management Teams and Teachers in Public Secondary Schools in Kuala Lumpur, Malaysia
}

\author{
Wei Yan, Jainabee L.S. Md. Kassim, Mohd Izham HJ Mohd Hamzah, Jamil Bin Ahmad \\ Faculty of Education, National University of Malaysia, Bangi, 43600, Malaysia \\ yanweiukm@sina.cn
}

\begin{abstract}
The objective of this case study is to explore the situations of supervision practices between members of school management teams and teachers in Kuala Lumpur, Malaysia. The conceptual framework developed on the "Model of Supervisory Practice" by Pajak (1990), then, the questionnaires were set up with qualified validity and reliability. 237 (95.6\%) managers and 302 $(82.3 \%)$ teachers participated in the survey randomly, then, the primary data were analyzed by professional statistic research methods. The research results are as following: Firstly, the overall level of supervision practices by managers' viewpoint $($ mean $=4.213$ ) is at very high level $(4.21-5.00)$, meanwhile, teachers' viewpoint $($ mean $=3.705)$ is at high level $($ mean $=3.41-4.20)$. Secondly, based on the demographic factor of gender, managers don't have significant differences among five dimensions; in contrast, male teachers have higher level of mean scores than female teachers significantly, on the dimension of staff development $(\mathrm{t}=2.097, p=0.037)$, instructional programs $(\mathrm{t}=3.262, p=0.001)$ and motivating $\&$ organizing $(\mathrm{t}=$ 2.334, $p=0.024)$. Thirdly, based on the demographic factor of role currently hold, principals have higher mean scores than senior assistants significantly on the dimensions of communication $(\mathrm{t}=$ 2.555, $p=0.011)$, instructional programs $(\mathrm{t}=2.160, p=0.032)$, motivating \& organizing $(\mathrm{t}=2.440, p=0.015)$ and curriculum $(\mathrm{t}=$ $3.587, p=0.000)$.

Index Terms - Instructional Supervision, Educational Management, Staff Development, Motivating \& Organizing.
\end{abstract}

\section{Introduction}

Supervision is an important aspect of educational management, it could draw together discrete elements of instruction into whole school actions [1], as well as reduce the risk of burn-out, enhance work performance and increase job satisfaction [2]. The development of supervision experienced a long and gradual process in its history which includes six representative stages from late nineteenth century to current. The mentioned stages are supervision as inspection, supervision as social efficiency, democratic supervision, scientific supervision, supervision as leadership and clinical supervision.

Although Malaysian supervision has independent system and advanced ethos, the situations of related dimensions still have problems inevitably in daily life. The Malaysian Ministry of Education has tabled reforms of several supervision practices which include teachers' development and curriculum. Despite this proposal, Malaysian principals have been found to be ignoring their duty as educational supervisors [3], and little attention has been paid to supervision by school management teams [4]. It is clear that all of members of school management teams should pay more attention to supervision practices, since it has a profound influence on school operation and outcomes. Meanwhile, appeal all of related members who are in the area of supervision in the whole society pay more attention to supervision for better school management and school outcomes is also an important objective of this study.

\section{Research Methodology}

In this study, the sample selection was based on the multistage cluster sampling technique. The sample was selected from each zone and the proportion was made up by the representatives from the total number of school managers and teachers in four zones in Kuala Lumpur, Malaysia. It was stated that the bigger the sample size, the smaller error will likely to happen in the population [5].

Based on the official data of Ministry of Education in Malaysia, the population of managers is 696 and the population of teachers is 7813 . The criterion for sample size was based on the recommendation by Krejcie and Morgan [6]. There were 248 managers and 367 teachers should be selected in Kuala Lumpur, Malaysia, then, 237 (95.6\%) managers and $302(82.3 \%)$ teachers returned effective questionnaires.

\section{A. Questionnaires}

Based on Pajak's model [7], the questionnaire for this research consisted of 70 items which based on five dimensions that communication, staff development, instructional programs, motivating \& organizing and curriculum. The validity was confirmed by three experts; meanwhile, the reliability was also confirmed by the pilot study.

\section{B. Interpretation of Mean Score}

The 5-point Likert type scale was used in this study which are 1 (Strongly Disagree), 2 (Disagree), 3 (Partially Agree), 4 (Agree) and 5 (Strongly Agree). Then, the levels of mean scores were divided into five ranges [8]. 
TABLE 1: Interpretation of Mean Score

\begin{tabular}{|c|c|}
\hline Mean Score & Interpretation of Mean Score \\
\hline $1.00-1.80$ & Very Low \\
\hline $1.81-2.60$ & Low \\
\hline $2.61-3.40$ & Moderate \\
\hline $3.41-4.20$ & High \\
\hline $4.21-5.00$ & Very High \\
\hline
\end{tabular}

Source: Dr. Jamil Bin Ahmad (2012), Faculty of Education, National University of Malaysia.

\section{Results}

\section{A. Levels of Supervision Practices}

On the one hand, the overall level $($ mean $=4.213)$ of supervision practices is at very high level by managers' standpoint. The dimensions of communication $($ mean $=4.314)$ and staff development $($ mean $=4.287)$ are at very high level (4.21 to 5.00 ), meanwhile, other three dimensions which are instructional programs $($ mean $=4.152)$, motivating and organizing $($ mean $=4.150)$ and curriculum $($ mean $=4.061)$ are at high level (3.41 to 4.20). Therein, the dimension of communication is at the highest level, then, the dimension of curriculum is at the lowest level. On the other hand, the overall level $($ mean $=3.705)$ of supervision practices is at high level by teachers' standpoint, at the same time, all of dimensions of supervision practices which are communication (mean $=$ 3.778), staff development (mean $=3.712)$, instructional programs (mean $=3.633$ ), motivating and organizing (mean $=$ 3.664) and curriculum (mean $=3.682)$ are at high level $(3.41$ to 4.20). Among of these dimensions, the dimension of communication is also at the highest level which is same with managers' standpoint, then, the weakest dimension is instructional programs.

TABLE 2: Levels of Supervision Practices between Managers and Teachers in Kuala Lumpur, Malaysia

\begin{tabular}{|l|l|r|r|r|r|}
\hline $\begin{array}{l}\text { Supervision } \\
\text { Practices }\end{array}$ & $\mathrm{M} \& \mathrm{~T}$ & $\mathrm{~N}$ & Mean & $\mathrm{SD}$ & $\begin{array}{r}\text { Interpretation } \\
\text { of Mean }\end{array}$ \\
\hline \multirow{4}{*}{ Com } & Managers & 237 & 4.314 & .464 & Very High \\
\cline { 2 - 6 } & Teachers & 302 & 3.778 & .561 & High \\
\hline SD & Managers & 237 & 4.287 & .463 & Very High \\
\cline { 2 - 6 } & Teachers & 302 & 3.712 & .572 & High \\
\hline \multirow{4}{*}{ IP } & Managers & 237 & 4.152 & .519 & High \\
\cline { 2 - 6 } & Teachers & 302 & 3.633 & .619 & High \\
\hline \multirow{3}{*}{ M \& O } & Managers & 237 & 4.150 & .516 & High \\
\cline { 2 - 6 } & Teachers & 302 & 3.664 & .617 & High \\
\hline Curr & Managers & 237 & 4.061 & .608 & High \\
\cline { 2 - 6 } & Teachers & 302 & 3.682 & .622 & High \\
\hline \multirow{3}{*}{ Overall } & Managers & 237 & 4.213 & .515 & Very High \\
\cline { 2 - 6 } & Teachers & 302 & 3.705 & .603 & High \\
\hline
\end{tabular}

Indicators: Com (Communication), SD (Staff Development), IP (Instructional Programs), M \& O (Motivating \& Organizing), Curr (Curriculum)

\section{B. The Differences in Supervision Practices by Demographic Factors \\ 1) Gender between School Management Teams and Teachers \\ According to the Table 3, there are no significant} differences in scores for male managers and female managers on the five dimensions of supervision practices. Meanwhile, male teachers have higher level of mean scores than female teachers significantly, on the dimension of staff development $(\mathrm{t}$ $=2.097, p=0.037)$, instructional programs $(\mathrm{t}=3.262, p=$ $0.001)$ and motivating \& organizing $(\mathrm{t}=2.334, p=0.024)$.

TABLE 3: $\mathrm{T}$ - test Results by Gender

\begin{tabular}{|c|c|c|c|c|c|c|}
\hline SP & M \& T & Gender & Mean & SD & t-value & $p$ \\
\hline \multirow[t]{4}{*}{ Com } & \multirow[t]{2}{*}{ Managers } & Male & 4.347 & .423 & .551 & .582 \\
\hline & & Female & 4.306 & .475 & & \\
\hline & \multirow[t]{2}{*}{ Teachers } & Male & 3.888 & .560 & 1.326 & .186 \\
\hline & & Female & 3.762 & .560 & & \\
\hline \multirow[t]{4}{*}{ SD } & \multirow[t]{2}{*}{ Managers } & Male & 4.306 & .508 & .326 & .745 \\
\hline & & Female & 4.282 & .451 & & \\
\hline & \multirow[t]{2}{*}{ Teachers } & Male & 3.888 & .684 & 2.097 & $.037 *$ \\
\hline & & Female & 3.685 & .549 & & \\
\hline \multirow[t]{4}{*}{ IP } & \multirow[t]{2}{*}{ Managers } & Male & 4.255 & .532 & 1.568 & .118 \\
\hline & & Female & 4.125 & .514 & & \\
\hline & \multirow[t]{2}{*}{ Teachers } & Male & 3.925 & .605 & 3.262 & $.001 *$ \\
\hline & & Female & 3.588 & .610 & & \\
\hline \multirow[t]{4}{*}{$\mathrm{M} \& \mathrm{O}$} & \multirow[t]{2}{*}{ Managers } & Male & 4.184 & .527 & .515 & .607 \\
\hline & & Female & 4.141 & .515 & & \\
\hline & \multirow[t]{2}{*}{ Teachers } & Male & 3.913 & .742 & 2.334 & $.024 *$ \\
\hline & & Female & 3.626 & .588 & & \\
\hline \multirow[t]{4}{*}{ Curr } & \multirow[t]{2}{*}{ Managers } & Male & 4.010 & .800 & -.530 & .598 \\
\hline & & Female & 4.075 & .549 & & \\
\hline & \multirow[t]{2}{*}{ Teachers } & Male & 3.838 & .702 & 1.701 & .090 \\
\hline & & Female & 3.658 & .607 & & \\
\hline
\end{tabular}

Indicators: Com (Communication), SD (Staff Development), IP (Instructional Programs), M \& O (Motivating \& Organizing), Curr (Curriculum)

\section{2) Role Currently Hold by School Management Teams}

This independent factor was divided into principal and senior assistant in questionnaires (Set A) which were distributed to members of school management teams. Meanwhile, this independent factor doesn't appear in teachers' questionnaires (Set B), since teachers are regarded as one group in this study. Thus, the analysis of role currently hold only shows data from managers' standpoint.

Based on the dimensions of communication $(\mathrm{t}=2.555, p$ $=0.011)$, instructional programs $(\mathrm{t}=2.160, p=0.032)$, motivating \& organizing $(\mathrm{t}=2.440, p=0.015)$ and curriculum $(\mathrm{t}=3.587, p=0.000)$, there are significant differences between principals and senior assistants, except the dimension of staff development $(\mathrm{t}=0.610, p=0.542)$. 
TABLE 4: T - test Results by Role Currently Hold

\begin{tabular}{|l|l|r|r|r|r|}
\hline SP & Role & Mean & SD & t-value & $p$ \\
\hline \multirow{2}{*}{ Com } & Principal & 4.588 & .404 & 2.555 & $.011^{*}$ \\
\cline { 2 - 6 } & Senior Assistant & 4.293 & .462 & & \\
\hline \multirow{2}{*}{ SD } & Principal & 4.353 & .580 & .610 & .542 \\
\cline { 2 - 6 } & Senior Assistant & 4.282 & .453 & & \\
\hline \multirow{2}{*}{ IP } & Principal & 4.412 & .618 & 2.160 & $.032^{*}$ \\
\cline { 2 - 6 } & Senior Assistant & 4.132 & .506 & & \\
\hline \multirow{2}{*}{ M \& O } & Principal & 4.441 & .527 & 2.440 & $.015^{*}$ \\
\cline { 2 - 6 } & Senior Assistant & 4.127 & .510 & & \\
\hline \multirow{2}{*}{ Curr } & Principal & 4.559 & .464 & 3.587 & $.000^{*}$ \\
\cline { 2 - 6 } & Senior Assistant & 4.022 & .602 & & \\
\hline
\end{tabular}

Indicators: Com (Communication), SD (Staff Development), IP (Instructional Programs), M \& O (Motivating \& Organizing), Curr (Curriculum)

\section{Discussion}

\section{A. Levels of Supervision Practices}

Although overall level of supervision practices which is from managers' standpoint is higher than teachers' standpoint, this phenomenon is normal and could be accepted calmly and patiently, since there are at least four reasons could be listed that i) The research finding is gratifying that both of managers and teachers' standpoints about supervision practices are at good level which is could be praised. ii) Managers' higher level not only shows the results of managers' self-evaluation are higher than teacher' evaluation, but also could express managers' confidence for their daily work; meanwhile, this phenomenon is accord with human social characteristic which should not be criticized. iii) The gap of mean scores which is between managers and teachers is not large. Thus, it could be considered that managers and teachers have similar standpoints which are about the levels of supervision practices. iv) This study is a personal research thesis, thus, the research findings should be accepted without bias and without favors, whatever the findings are positive or negative.

In addition, managers consider that the dimension of communication has the highest level and the dimension of curriculum has the lowest level. It means that managers have strong confidence in communication in their managerial work and the dimension of curriculum is soft spot. In contrast, teachers' data could show their opinion about each dimension is average and all of them are at high level, among of them, the dimension of communication is the highest too which is same with managers' opinion, it means that teachers agree with managers' standpoint and confirm managers' abilities of communication. This study suggests that managers should keep on top of communication, meanwhile, try their best to promote the level of curriculum for better supervision practices, since the importance of curriculum is self-evident.

Based on the dimension of communication, the barriers should be realized, since it stands in the breach, in order to keep on top, then, achieve continuous progress. Breshears [9] proposed four main barriers which should be overcame for better effectiveness of communication, i) Physical barriers, ii)
Psychological barriers, iii) Cultural barriers and iv) Language barriers. Bryant [10] proposed barriers which are i) Listening, ii) Jumping to conclusion and iii) Emotion. In addition, this study suggests that managers should be diligent in selfexamination, since this is not only the traditional virtue, but also the job demand.

Based on the weak research results of curriculum, this study suggests that managers could improve curriculum by related opinions which are i) Prepare enough time to revise curriculum for better effect, ii) Curriculum should not be treated as a simple product, but a complex process of teaching and learning, iii) Necessary reform should be designed and implemented by managers for changing situation, iv) Efficient curriculum need positive competition among teachers, v) The scores of curriculum should not to be the only one focus of teaching activities, it will lead to negative consequence which is inverse of focus [11].

\section{B. Gender between School Management Teams and Teachers}

On the one hand, male managers and female managers have the same level of supervision practice based on five dimensions, this phenomenon means male and female have similar attitude about their working which could be considered a positive phenomenon. On the other hand, female teachers' mean scores are lower than male teachers significantly based on dimensions of staff development, instructional programs and motivating and organizing. It means the situation of these three dimensions of supervision practices is unbalanced by teachers' standpoints which are between male teachers and female teachers. Thus, managers should better pay more attention to female teachers about these three dimensions and try to improve teachers' satisfaction evenly.

\section{Role Currently Hold by School Management Teams}

This study identified that principals and senior assistants have significant differences about four dimensions of supervision practice which are communication, instructional programs, motivating and organizing and curriculum, except the dimension of staff development, even so, principals still have higher mean scores than senior assistants based on this dimension.

This phenomenon is reasonable, on the one hand, principals manage the whole secondary school; thus, their opinions about the level of supervision practices should be the overall situation. On the other hand, senior assistants are in different departments in secondary schools, they face different daily affairs which lead to the data reflect that a part of senior assistants have high level of supervision practices and a part of senior assistants have low level of supervision practices. Thus, the overall mean by senior assistants is lower than principals. In addition, principals have higher status than other normal managers, it certainly would lead to principals have more smooth daily working and higher mean scores of supervision practices. Based on this research results, this study suggests that principals who are in secondary schools in Kuala Lumpur should try to pay more attention to different situations of 
different departments and offices, then, assist and guide senior assistants to overcome difficulties for their better working situation, meanwhile, the feedback should also be emphasized for improving supervision practices evenly.

\section{Conclusion}

The objective of research about supervision practices is improving working efficacy, then, achieving school success, thus, all of dimensions of supervision practices should be emphasized, in order to achieve the objective. Firstly, successful schools are filled with great communicators is abundant and overwhelmingly clear [12]. It is the approach that understands each other and set up positive personal or professional relationships among people in the society. There is no doubt that scientific, effective and friendly communication is necessary to any success secondary schools in any countries. Secondly, staff development is the approach which is achieving teachers' value of occupation; meanwhile, this dimension could influence the recognition deeply. If teachers could not achieve their value all the time, it certainly will bring negative influence to teachers' spirit and working efficiency, then, it could damage to school operation and development, furthermore, it is almost impossible to achieve school success. Thus, managers have responsibility to offer fair, effective and suitable system of staff development to each teacher for their growth. In fact, the essence of staff development is one kind of investment by managers in secondary schools; moreover, the profit is certain which improve school operation and promote school development through stronger level of teachers' abilities. This study wants to emphasize that this investment is wise, since excellent quality and reasonable price. Thirdly, the dimension of instructional programs has closed relationships with teaching quality and instructional focuses. A good system of instructional programs is the premise of good curriculum [13], as well as the teaching outcomes and teachers' achievements. Thus, school managers must guide teachers and share their useful experience to teachers to avoid negative factors during this process, in order to achieve positive results. Fourthly, motivating and organizing exist in any organizations in any countries, since it is indispensable in managerial practices. School managers need encourage teachers through this approach for their working enthusiasm; meanwhile, it must be fair, reasonable and humanized. In addition, this study considers that the factors of tradition, culture and taboos should be taken into account during this process. Fifthly, curriculum is related to classroom teaching and students' scores directly. This study suggests that managers should allow, even encourage teachers to share more life experiences with students, meanwhile, encourage students to take part in social activities. The reason is that how to growth is more important than how to get higher exam scores, in other word, the real objective of education is that guide students how to live better in the society correctly.

\section{Reference}

[1] Glickman, C.D. \& Gordon, S.P. \& Ross-Gordon, J.M., 2007. Supervision and Instructional Leadership: A Developmental Approach. Reilly, E. $7^{\text {th }}$ ed. USA: Pearson Education.

[2] Rico. 2010. Supervision. Resilient Individuals, Communities \& Organizations Training, Processes \& Strategies. PO Box 1328, WODEN ACT 2606. http://www.rico.com.au/training/life_skills/supervision.htm (20 August 2012).

[3] Nek, K.Y.Y \& Jamal, N.Y. \& Salomawati, I., 2000. The School Principals' Roles in Teaching Supervision in Selected Schools in Perak, Malaysia. Asian Journal of Business and Management Sciences. 1(2): $50-55$.

[4] Suseela, M., 2007. Teacher Learning in Malaysia: Problems and Possibilities of Reform. Kuala Lumpur: University of Malaya.

[5] Creswell, J.W. 2005. Educational Research. Planning, Conducting, and Evaluating Quatitative and Qualitative Research. In OTED 1083 \& OTED 1085 Qualitative Research Methods Readings. Sydney: Pearson Education Australia.

[6] Krejcie, R. V. \& Morgan, D. W. 1970. Determining Sample Size for Research Activities. Educational and Psychological Measurement. 30, 607-610.

[7] Pajak, E. 1990. Identification of Dimensions of Supervisory Practice in Education: Reviewing the Literature. Document ED 320285.

[8] Jamil, H \& Razak, N.A. \& Raju, R. \& Rashid, A.M. 2010. Universiti Sains Malaysia. 85-102.

[9] Breshears, D. 2010. Possible Barriers to Communication. (online) http://www.ehow.com/list_6741678_possible-barrierscommunication.html (10 April 2012)

[10] Bryant, B.J. 1999-2011. Barriers to Effective Communication in Supervision (online). http://www.ehow.com/way_5446177_barrierseffective-communication-supervision.html (18 July 2012)

[11] Weber, S.M. 2010. Five Barriers to Curriculum Development (online), http://www.scribd.com/doc/64771788/Five-Barriers-to-CurriculumDevelopment (06 August 2012).

[12] Whitaker, T \& Zoul, J. 2008. Core Factors for School Success. Eye on Education, 6 Depot Way West, Suite 106, Larchmont, NY 10538.

[13] Yu, S.C. 2012. The System of Teachers' Instructional Programs. (online) http://www.chinavalue.net/Biz/Blog/2012-6-22/912556.aspx (05 December 2012). 